\title{
Primary hypomagnesemia with secondary hypocalcemia
}

INSERM

\section{Source}

INSERM. (1999). Orphanet: an online rare disease and orphan drug data base. Primary

hypomagnesemia with secondary hypocalcemia. ORPHA:30924

Primary hypomagnesemia with secondary hypocalcemia (PHSH) is a form of familial primary hypomagnesemia (FPH, see this term), characterized by severe hypomagnesemia and secondary hypocalcemia associated with neurological symptoms, including generalized seizures, tetany and muscle spasms. PHSH may be fatal or may result in chronic irreversible neurological complications. 